Curr Psychiatry Rep. 2013 November ; 15(11): . doi:10.1007/s11920-013-0406-z.

\title{
Bereavement and Complicated Grief
}

\author{
M. Katherine Shear, MD, \\ Columbia University School of Social Work, Room 829, 1255 Amsterdam Avenue, New York, NY \\ 10027, Phone: (212) 851-2176, Fax: (212) 851-2175
}

Angela Ghesquiere, $\mathrm{PhD}$, and

21 Bloomingdale Road, 7 South, White Plains, NY 10605, Phone: (914) 997-8683, Fax: (914) 682-6979

Kim Glickman, PhD, LCSW

Department of Social Sciences, School of Health and Behavioral Sciences, York College of the City University of New York, Phone: (718) 262-2616, Fax: (718) 262-3790

M. Katherine Shear: ks2394@columbia.edu; Angela Ghesquiere: ang2042@med.cornell.edu; Kim Glickman: glickman@york.cuny.edu

\section{Abstract}

Bereavement is a common experience in adults age 60 and older. Loss of a loved one usually leads to acute grief characterized by yearning and longing, decreased interest in ongoing activities, and frequent thoughts of the deceased. For most, acute grief naturally evolves into a state of integrated grief, where the bereaved is able to reengage with everyday activities and find interest or pleasure. About 7\% of bereaved older adults, however, will develop the mental health condition of Complicated Grief (CG). In CG, the movement from acute to integrated grief is derailed, and grief symptoms remain severe and impairing. This article reviews recent publications on the diagnosis of CG, risk factors for the condition, and evidenced-based treatments for CG. Greater attention to complicated grief detection and treatment in older adults is needed.

\section{Keywords}

Complicated grief; Bereavement; Older adults; Grief; Loss; Attachment theory; Symptoms;

Treatment; Psychiatry

\section{INTRODUCTION}

"Grief turns out to be a place none of us know until we reach it... Nor can we know ahead of the fact ... the unending absence that follows, the void, the very opposite of meaning, the relentless succession of moments during which we will confront the experience of meaninglessness itself."

\footnotetext{
Correspondence to: M. Katherine Shear, ks2394 e columbia.edu.

Compliance with Ethics Guidelines

Conflict of Interest

M. Katherine Shear has received grants from National Institute of Mental Health (NIMH) and American Foundation for Suicide Prevention, travel support from NIMH, and compensation for expert testimony from a private individual.

Angela Ghesquiere is the recipient of an NIMH research fellowship in geriatric mental health services (T32 MH073553, PI: Bartels).

Kim Glickman declares that she has no conflict of interest.

Human and Animal Rights and Informed Consent

This article does not contain any studies with human or animal subjects performed by any of the authors.
} 
Didion's book is a vivid and powerful description of her grief following the sudden death of her 71-year-old husband, her close companion for more than 40 years. She finds the experience to be (perhaps thankfully) unlike anything she could have imagined. In this, Didion's response is not unique. Though bereavement is an event experienced by all humanity, there are few events as unfamiliar or as unsettling. Clinicians can assist the bereaved to cope with bereavement and its disruptive consequences. However, treatment of the bereaved can be controversial because the pain and disruption are universal and intrinsic to the situation. It can be challenging to distinguish between typical bereavement responses and more intense reactions that could constitute a mental health disorder.

Bereavement and its care are particularly relevant to older adults because they experience bereavement at a much higher rate than younger adults; one study found that over $70 \%$ of older adults experienced bereavement in a 2.5 year period (2). Spousal loss is very common (3), but deaths of friends or non-spousal relatives (especially siblings) may account for the greatest proportion of losses among older adults (2) (4). In order to be optimally supportive to bereaved older adults, it is important for clinicians to be knowledgeable. The purpose of this paper is to provide detail on recent research on bereavement and bereavement care in older adults that may be useful to clinicians.

We begin by clarifying terminology. We use the term bereavement to refer to the experience of having lost a loved one, not the response to such a loss. Grief refers to the psychobiological response to bereavement. Acute grief is the initial response, often intense and disruptive. Integrated grief is the permanent response after adaptation to the loss, in which satisfaction in ongoing life is renewed. Complicated grief is a form of prolonged acute grief, where the term complicated is used in the medical sense of a superimposed process that impedes healing. Complicated grief is a distinct mental health disorder.

Mourning denotes the array of psychological processes set in motion by the loss to facilitate adaptation (5).

\section{IS GRIEF AN ILLNESS?}

Some say grief should not be pathologized, as though a clinician would choose to create pathology when our whole purpose is to relieve it. Inflammation is the painful, universal response to exposure to certain bacteria, yet we do not debate whether a clinician is pathologizing a natural human experience by diagnosing and treating it. However, mental disorders carry the added burden of stigma and there is the diagnostic challenge that most mental disorders exist on a continuum with normal functioning. Perhaps for these reasons, a diagnosis can sometimes seem like a gratuitous negative judgment rather than a first step in accessing appropriate treatment.

Again, Didion's clearly articulated discourse is helpful. She writes: "The power of grief to derange the mind has... been exhaustively noted.... The mourner is in fact ill, but because this state of mind is common and seems so natural... we do not call [it] an illness" (p.34, quoting Melanie Klein). Freud also felt that grief should not be considered a mental disorder (6), and many clinicians follow Freud and Klein and do not regard any grief response as an illness. Yet, many bereaved people are suffering. What then is the role of clinicians in the management of grief? When and how should clinicians provide help?

The answers to these questions are not clear-cut. Dyregrov and Dyregrov (7) stress the importance of relying on existing social supports for bereaved people, and we concur with this perspective. Providing comfort and support in the early bereavement period is usually 
very natural for family, friends, neighbors and others in the community. There are prescribed periods of contact such as visitation, funeral, sitting shiva and other ritualistic gatherings. Others can be helpful as caring listeners who share in reminiscence and join in seeking answers to unanswerable questions; they must resist the urge to provide answers or gratuitous advice. As time goes on, though, others can provide gentle encouragement to reengage in ongoing life, even when the bereaved person is not well motivated to do so. For most bereaved individuals, natural social supports will be sufficient.

Dyregrov and Dyregrov (7) point out, however, that certain difficult circumstances of a death can leave virtually everyone desirous of professional support. For example, after a suicide, up to $80 \%$ of bereaved people say that they want professional help (8). When the bereaved do seek support, clinicians can add their voices to the chorus of support, bringing both their professional expertise and their humanity to the encounter. They can educate people about the rocky uncharted pathway ahead. However, they must be humble in their expertise. Informed clinicians can provide Sherpa-like guidance to bereaved people, walking by their side as they navigate the arduous path to rediscovery of meaning and purpose, and new possibilities for joy and satisfaction.

\section{THE CONSEQUENCES OF BEREAVEMENT IN OLDER ADULTS}

It is important that any clinicians working with bereaved older adults be aware that bereavement in older adults can be associated with a number of negative outcomes. Loss of a loved one is associated with worsening health, including weight loss, increased rates of illness and functional impairment $(9,10)$. Mostofsky et al. (11) analyzed data from the Determinants of Myocardial Infarction Onset Study (mean age 61; MIOS) and documented a 21.1-fold (95\% CI 13.1-34.1) increase in incidence of MI within 24 hours of learning of the death of a loved one. Incidence declined each subsequent day but remained significantly elevated for a month. Khanfer et al (12) studied older adults (average age 73) bereaved for 2 months, compared to age and sex-matched non-bereaved. Bereavement was associated with lower neutrophil superoxide production when challenged with bacteria or a protein kinase activator, and higher cortisol/DHEAS ratios that correlated with elevated depressive and anxiety symptoms. Another study assessed cardiovascular and immune functioning at 2 weeks and 6 months post-loss in bereaved relatives (average age 65) of patients who died in an ICU. The authors found changes in blood pressure, heart rate, sleep, neuroendocrine and immune functioning (13). Most of these changes normalized by 6 months post-loss, however.

Bereavement also appears to increase risk for mortality in the early period after the event. In a large primary care database in the United Kingdom, bereavement was associated with increased hazard of mortality, 1.25 (CI 1.21, 1.37), highest in the first 90 days. This finding was stronger for those with no recorded chronic medical conditions prior to the loss, and among those from high income communities (14). Spouses bereaved by unexpected death also have a higher rate of mortality (15). These increased mortality rates appear to primarily be attributed to suicide, accidents, heart disease and cancer (9).

In addition, bereavement is associated with changes in social and emotional factors in older adults, including a decrease in satisfaction and well-being and an increase in loneliness and social isolation $(9,16)$. However, there appear to be substantial variations in these outcomes based on socioeconomic factors. Arbuckle and De Vries (17) examined functioning, life satisfaction and hopefulness for the future 2-15 years after older adults lost a child or a partner. They found bereaved elders experienced less satisfaction and less hopefulness but greater self-efficacy than controls who were not bereaved. Negative social and health effects were significantly greater among women, and less education and income were also 
associated with worse bereavement outcomes. Another study found that, in households where married couples had high-loss intra-household financial dependency, after widowhood, in households with high financial dependency, bereaved men (the breadwinners) compared to married controls, experienced a significant loss in global wellbeing, whereas both widows and widowers experienced greater bereavement-related psychosocial distress. Bereaved women experienced greater financial distress, regardless of pre-loss dependency status (18).

\section{COMPLICATED GRIEF IN OLDER ADULTS}

For most bereaved older adults, the health and emotional consequences of bereavement resolve in a few months, and pre-loss functioning is restored (19). However, for a clinically significant minority, complications derail the natural mourning process and prolong acute grief, resulting in a mental health condition. There is ongoing debate over what this condition should be called. Our group has used the term "complicated grief" (CG) because 1) much of the literature has been published using that designation and 2) it is a nonpejorative yet descriptive term.

George Engel (20) conceived of grief as analogous to infection or injury, and we agree with this conceptualization (21). Thus, we also use the term "complicated" in the medical sense of a superimposed condition that impedes the course of another health problem (in this case, typical acute grief). For some bereaved individuals, the natural healing process is interfered with by various complications, just as a wound does not heal properly when it becomes infected. The injury analogy is apt for bereavement because healing requires painful emotional activation similar to the physical pain of a wound. Grief becomes complicated when there are problems related to the circumstances, consequences or context of the loss or by an internal problem with the adaptation process. Didion does not like the term "healing," and the analogy is not perfect, but considering a loss to be similar to a serious injury recognizes the severity of the pain and disruption, the possibility for complications, and the potential usefulness of clinical attention, without implying an underlying problem.

CG was first proposed as a diagnostic entity for DSM IV by Hartz (22). Horowitz et al. (23) published a seminal paper testing diagnostic criteria, and Prigerson et al published an influential series of papers with an evolving set of proposed criteria (e.g. $(24,25))$. However, the Prigerson criteria were based upon results of community studies with a small number of individuals with CG. Our group $(26,27)$ proposed a slightly different set of diagnostic criteria based upon clinical experience and a much larger data set of individuals with CG who sought help. The recently released $5^{\text {th }}$ edition of the American Psychiatric Association's Diagnostic and Statistical Manual (DSM-5) includes criteria for CG in the section on "Disorders Requiring Further Study." Here, the condition is called "Persistent Complex Bereavement Disorder" (28). Table 1 outlines the DSM-5 criteria for diagnosis in adults.

While these various criteria sets differ in some respects and consensus still needs to be reached, all proposals include symptoms of prolonged acute grief, such as frequent intense yearning, intense sorrow and emotional pain, preoccupation with the deceased and/or circumstances of the death, excessive avoidance of reminders of the loss, difficulty accepting the death, feeling alone and empty, and feeling that life has no purpose or meaning without the deceased person. Identified CG symptoms also meet many of the criteria outlined by Stein and colleagues (29) needed to confirm validity of a new diagnostic entity. We and others are currently conducting a field trial of the proposed DSM-5 CG criteria, as well as alternative proposed criteria. We believe that consensus will be reached in the near future. 
As with all mood and anxiety disorders, the co-occurrence of complicated grief and major depressive disorder (MDD), $(30,31)$ is common, with studies finding that $25 \%$ of those with bereavement-related depression have CG, and $36-55 \%$ of those with CG have comorbid depression (32-34). However, CG has been found to constitute a distinct cluster of symptoms which can be distinguished from depression $(23,35)$. Table 2 outlines clinical differences between CG and MDD. It is important to identify CG even when it is comorbid with depression because $\mathrm{CG}$ has unique clinical features and appears to require unique treatment. Treatment of CG in patients with depression is associated with reductions in depressive symptoms (36) but the reverse is not true (37). More detail on CG treatment is provided below.

A recent population-based survey found $6.7 \%$ of bereaved individuals develop CG, and individuals 61 and older had more than double the rate $(9 \%)$ of younger adults. Older women, in particular, had a rate of CG $(9.6 \%)$, much higher than that of younger adults (2.7\%) (38). CG can be chronic and persistent, markedly interfering with functioning. For example, Stammel et al. (39) surveyed 775 Cambodians who had lost at least one family member during the Khmer Rouge regime and found 14\% endorsed CG 30 years later.

CG can be reliably detected with standardized measures, such as the Inventory of Complicated Grief (ICG) (40). Reliable measures of CG have also recently been developed and tested for people with intellectual disabilities (41) and validated in other languages, such as Japanese (42). Most people with complicated grief (CG) are aware that something is wrong but don't know what it is, and are relieved to receive a diagnosis (43).

People with CG show a range of cognitive and affective differences from bereaved people without CG. Gupta and Bonanno (44) found the ability to flexibly enhance or suppress emotional expression at will was reduced in CG. Burton et al (45) found CG associated with less "forward coping", defined as the ability to think optimistically, attend to the needs of others, maintain plans and goals, remain calm, reduce painful emotions and be able to laugh. Golden and Dalgleish (46) studied 3 groups of midlife adults and found significant relationships between CG symptoms and both self-devaluation and negative self-related cognitions about the future. Those with CG also had greater negative cognitions about the future for close others. Bereaved individuals had high rates of self-related counterfactual thoughts about the death. Consistent with clinical observations, those with CG had these thoughts significantly more frequently and the thoughts were associated with greater distress. Also consistent with clinical observations, Boelen (47) asked bereaved individuals to write a list of 7 goals and found those with CG produced less specific goals, and reported lower sense of control and lower likelihood of achieving goals.

CG is associated with negative health and mental health consequences in older adults, beyond that of bereavement itself. Prigerson et al. (48) found that the risk of hypertension is 10 times greater among older adult widowed subjects who met criteria for CG compared to those who do not, and sleep impairment is associated with CG in older adults (49). Suicidality is twice as high among widowed older adults with CG than those without CG (50).

Recent reviews (51-57) summarize possible risk factors, for CG and suggest these are seen across samples, nationalities and age groups. CG is associated with female gender, low education, older age, low socioeconomic status, and low social support both before and after the death. A history of anxiety disorders or depression before the death and past history of multiple trauma or loss, also appear to be risk fators. Several investigators found that spiritual belief systems may decrease risk for developing CG (58-60). Denckla et al. (61) compared ratings on healthy dependency, destructive overdependence and dysfunctional 
detachment among a small group of bereaved middle aged people with and without CG and found that those with CG were more likely to have dysfunctional detachment.

CG also tends to occur after loss of a very close relationship with the deceased, such as loss of a spouse. Loss of a child poses an espcially high risk (62). Traumatic circumstances of the death, a lack of preparation, or difficult interactions with medical or other staff at the time of the death can increase the risk of CG. Chiu et al (60) found CG was associated with perceived general disapproval from others, longer duration of caregiving, and medical disease history in the caregiver. Use of hospice care decreased risk. Kramer et al (54) found higher CG symptoms in caregivers from families with low conflict before the end of life but higher conflict at the end of life, in those who had family members with difficulty accepting the illness, and among caregivers with greater fear of death.

\section{COMPLICATED GRIEF TREATMENT}

Given that CG can be reliably identified and differentiated from other mental disorders, and given its prevalence, we believe there is a need for an effective treatment. To meet this need, we developed complicated grief treatment (CGT), a 16-week individual treatment that is guided by an attachment theory model of grief. According to this model, the death of a loved one provokes an acute crisis of attachment with activation of the attachment working model and associated proximity seeking. This activation results in symptoms of yearning, longing and preoccupation with thoughts and memories of the deceased that alternate with a desire to escape from the painful reality. The loss also triggers a natural mourning process that leads the bereaved person to find a way to make peace with the finality and consequences of the loss, revise the internal working model and redefine life goals and plans. Sometimes this process is derailed by complications that impede the natural healing process. CGT seeks to address these complications and to reinvigorate the natural healing process. A set of lossrelated and restoration-related strategies and procedures are used to do this.

We published the first randomized controlled treatment trial for complicated grief (36). Funded by the National Institute of Mental Health, this study showed CGT was superior to Interpersonal Psychotherapy (IPT). A replication of this study in older adults is nearly complete, and a third multi-site study is underway. In a smaller study conducted at multiple sites, Boelen et al. (63) reported similar findings, comparing Cognitive Behavioral Treatment (CBT) with supportive counseling for $\mathrm{CG}$ and found a significant reduction in CG symptoms and general psychopathology in the CBT group compared to supportive counseling. A number of small studies using a similar intervention have now been published, including Acierno et al (64), Asukai et al (65), Rosner et al (66), Papa et al (67) and Supiano and Luptak (68). Wagner et al. (69) tested the effectiveness of an internet-based cognitive behavioral therapy for CG. Taken together, results of these studies are encouraging and suggest that complicated grief can be effectively treated by identifying CG, addressing grief complications and facilitating the natural healing process.

Pharmacotherapy might also be helpful to people with CG. Simon et al. (2008) found that patients taking antidepressants were more likely to complete CGT, with no such effect on completion rates for IPT. Zygmont et al. (70) also found combination treatment with Paroxetine or Nortriptyline administered with CGT were effective in reducing grief symptoms. Results with medication alone are more mixed. Pasternak et al (71) and Reynolds et al. (37) found treatment with antidepressant medication reduced depression but not CG, whereas in an open pharmacotherapy trial Hensley et al. (72) found that Citalopram improved depressive, anxiety and grief symptoms. 


\section{CONCLUSIONS}

Bereavement is a common life experience among older adults. For most, an initial period of acute grief evolves naturally into integrated grief. The bereaved older adult still has feelings of yearning and sorrow, but these are not frequent or intense enough to be disruptive. Daily activities are interesting and life holds the possibility for finding joy and meaning. This population of bereaved older adults can benefit from psychoeducation and general support from clinicians. Approximately $7 \%$ of older adults will develop complications that derail the normal mourning process, however, resulting in the syndrome of complicated grief (CG), also called prolonged grief and persistent complex bereavement disorder. Treatments for CG have also been tested, with the 16-session Complicated Grief Treatment (CGT) showing the best evidence of efficacy, including a study in older adults.

There has been important progress in understanding and treating CG in older adults, but there is still much that needs to be done. Consensus regarding the best name for the disorder and agreement on a criteria set are important next steps to support both clinical and research efforts. More must be done to increase the public and professional awareness of CG, in order to help ensure that those suffering from the condition receive needed help. To this end, we have established a Center for Complicated Grief at the Columbia University School of Social Work, with resources accessible at www.complicatedgrief.org. Other areas which require exploration include better understanding of similarities and differences in treatment modalities for CG in older adults. Better understanding of how CGT works and for whom (mediators and moderators of treatment) is also needed. Elucidating what services those with CG are currently using in the community and whether these are effective is essential as well. In addition, research on the dissemination of CGT and its acceptability to both clinicians and older adults with CG is necessary. Prevention and early intervention efforts for CG may also be helpful and should be tested. In short, research efforts are needed to help reduce the sizable negative health and mental health burden of CG for older adults.

\section{References}

Recently published papers of particular interest have been highlighted as:

*Of importance

**Of major importance

1. Didion, J. The year of magical thinking. New York: A.A. Knopf; 2005.

2. Williams BR, Sawyer Baker P, Allman RM, Roseman JM. Bereavement among African American and White older adults. J Aging Health. 2007; 19:313-333. [PubMed: 17413138]

3. Federal Interagency Forum on Aging Related Statistics: Older Americans 2012: Key indicators of well-being. Retrieved August 30, 2012, from http://www.agingstats.gov/agingstatsdotnet/ Main_Site/Data/2012_Documents/Docs/EntireChartbook.pdf

4. Williams BR, Sawyer Baker P, Allman RM. Nonspousal family loss among community-dwelling older adults. Omega. 2005; 51:125-142.

5. Bowlby, J. Attachment and loss. New York, NY: Basic Books; 1980.

6. Freud, S. Mourning and melancholia. In: Strachy, TJ., editor. The standard edition of the complete works of Sigmund Freud, 1953-1974. Vol. 14. London: Hogarth Press; 1917. p. 243-258.

7. Dyregrov, K.; Dyregrov, A.; Raundalen, M. Effective grief and bereavement support: The role of family, friends, colleagues, schools, and support professionals. London and Philadelphia: Jessica Kingsley Publishers; 2008.

8. Dyregrov K. What do we know about needs for help after suicide in different parts of the world? A phenomenological perspective. Crisis. 2011; 32:310-318. [PubMed: 21940240]

Curr Psychiatry Rep. Author manuscript; available in PMC 2014 November 01. 
9. Stroebe M, Schut H, Stroebe W. Health outcomes of bereavement. Lancet. 2007; 370:1960-1973. [PubMed: 18068517]

10. Manzoli L, Villari P, GMP, Boccia A. Marital status and mortality in the elderly: a systematic review and meta-analysis. Soc Sci Med. 2007; 64:77-94. [PubMed: 17011690]

11*. Mostofsky E, Maclure M, Sherwood JB, et al. Risk of acute myocardial infarction after the death of a significant person in one's life: the Determinants of Myocardial Infarction Onset Study. Circulation. 2012; 125:491-496. Provides up-to-date detail on the health consquences of bereavment. [PubMed: 22230481]

12*. Khanfer R, Lord JM, Phillips AC. Neutrophil function and cortisol:DHEAS ratio in bereaved older adults. Brain Behav Immun. 2011; 25:1182-1186. Provides novel information on the biology of changes in health after bereavement. [PubMed: 21420485]

13. Buckley T, Morel-Kopp MC, Ward C, et al. Inflammatory and thrombotic changes in early bereavement: a prospective evaluation. Eur J Prev Cardiol. 2012; 19:1145-1152. [PubMed: 21900365]

14*. Shah SM, Carey IM, Harris T, et al. Do good health and material circumstances protect older people from the increased risk of death after bereavement? Am J Epidemiol. 2012; 176:689-698. Provides greater understanding of the pathways between bereavement and mortality. [PubMed: 23051600]

15. Shah SM, Carey IM, Harris T, et al. The effect of unexpected bereavement on mortality in older couples. Am J Public Health. 2013; 103:1140-1145. [PubMed: 23597341]

16. Anderson KL, Dimond M. The experience of bereavement in older adults. J Adv Nurs. 1995; 22:308-315. [PubMed: 7593952]

17. Arbuckle NW, de Vries B. The long-term effects of later life spousal and parental bereavement on personal functioning. Gerontologist. 1995; 35:637-647. [PubMed: 8543221]

$18 *$. Hallerod B. Gender inequality from beyond the grave: Intra-household distribution and wellbeing after spousal loss. Ageing Soc. 2013; 33:783-803. Useful detail exploring the associations between bereavement and functioning.

19. Chentsova Dutton Y, Zisook S. Adaptation to bereavement. Death Stud. 2005; 29:877-903. [PubMed: 16265796]

20. Engel GL. Is grief a disease? A challenge for medical research. Psychosom Med. 1961; 23:18-22. [PubMed: 13696798]

$21 *$ Shear MK. Grief and mourning gone awry: pathway and course of complicated grief. Dialogues Clin Neurosci. 2012; 14:119-128. Provides a useful overview, in more detail, of our groups' conceptualization of the development of complicated grief. [PubMed: 22754284]

22. Hartz GW. Adult grief and its interface with mood disorder: proposal of a new diagnosis of complicated bereavement. Compr Psychiatry. 1986; 27:60-64. [PubMed: 3948504]

23. Horowitz MJ, Siegel B, Holen A, et al. Diagnostic criteria for complicated grief disorder. Am J Psychiatry. 1997; 154:904-910. [PubMed: 9210739]

24. Prigerson HG, Shear MK, Jacobs SC, et al. Consensus criteria for traumatic grief. A preliminary empirical test. Br J Psychiatry. 1999; 174:67-73. [PubMed: 10211154]

25. Prigerson HG, Horowitz MJ, Jacobs SC, et al. Prolonged grief disorder: Psychometric validation of criteria proposed for DSM-V and ICD-11. PLoS Med. 2009; 6:e1000121. [PubMed: 19652695]

26*. Simon NM, Wall MM, Keshaviah A, et al. Informing the symptom profile of complicated grief. Depress Anxiety. 2011; 28:118-126. Exploration of diagnostic criteria for complicated grief. [PubMed: 21284064]

27*. Shear MK, Simon N, Wall M, et al. Complicated grief and related bereavement issues for DSM-5. Depress Anxiety. 2011; 28:103-117. Gives a more detailed overview of the argument for including complicated grief in the DSM-5. [PubMed: 21284063]

28. American Psychiatric Association. Diagnostic and statistical manual of mental disorders. 5. Arlington, VA: American Psychiatric Association; 2013.

29. Stein DJ, Phillips KA, Bolton D, et al. What is a mental/psychiatric disorder? From DSM-IV to DSM-V. Psychol Med. 2010; 40:1759-1765. [PubMed: 20624327]

30. Jacobs S, Hansen F, Kasl S, et al. Anxiety disorders during acute bereavement: risk and risk factors. J Clin Psychiatry. 1990; 51:269-274. [PubMed: 2365664] 
31. Simon NM, Shear KM, Thompson EH, et al. The prevalence and correlates of psychiatric comorbidity in individuals with complicated grief. Compr Psychiatry. 2007; 48:395-399. [PubMed: 17707245]

32. Sung SC, Dryman MT, Marks E, et al. Complicated grief among individuals with major depression: prevalence, comorbidity, and associated features. J Affect Disord. 2011; 134:453-458. [PubMed: 21621849]

33. Neria Y, Gross R, Litz B, et al. Prevalence and psychological correlates of complicated grief among bereaved adults 2.5-3.5 years after September 11th attacks. J Trauma Stress. 2007; 20:251-262. [PubMed: 17597124]

34. Shear KM, Jackson CT, Essock SM, Donahue SA, Felton CJ. Screening for complicated grief among Project Liberty service recipients 18 months after September 11, 2001. Psychiatr Serv. 2006; 57:1291-1297. [PubMed: 16968758]

35. Prigerson H, Frank E, Kasl SV, et al. Complicated grief and bereavement-related depression as distinct disorders: preliminary empirical validation in elderly bereaved spouses. Am J Psychiatry. 1995; 152:22-30. [PubMed: 7802116]

36. Shear K, Frank E, Houck PR, Reynolds CF 3rd. Treatment of complicated grief: a randomized controlled trial. JAMA. 2005; 293:2601-2608. [PubMed: 15928281]

37. Reynolds CF 3rd, Miller MD, Pasternak RE, et al. Treatment of bereavement-related major depressive episodes in later life: a controlled study of acute and continuation treatment with nortriptyline and interpersonal psychotherapy. Am J Psychiatry. 1999; 156:202-208. [PubMed: 9989555]

$38^{* *}$. Kersting A, Brahler E, Glaesmer H, Wagner B. Prevalence of complicated grief in a representative population-based sample. J Affect Disord. 2011; 131:339-343. Describes one of the few large population-based studies of complicated grief prevalence. [PubMed: 21216470]

39. Stammel N, Heeke C, Bockers E, et al. Prolonged grief disorder three decades post loss in survivors of the Khmer Rouge regime in Cambodia. J Affect Disord. 2013; 144:87-93. [PubMed: 22871529]

40. Prigerson HG, Maciejewski PK, Reynolds CF 3rd, et al. Inventory of Complicated Grief: a scale to measure maladaptive symptoms of loss. Psychiatry Res. 1995; 59:65-79. [PubMed: 8771222]

41. Guerin S, Dodd P, Tyrell J, et al. An initial assessment of the psychometric properties of the Complicated Grief Questionnaire for People with Intellectual Disabilities (CGQ-ID). Res Dev Disabil. 2009; 30:1258-1267. [PubMed: 19556102]

42. Ito M, Nakajima S, Fujisawa D, et al. Brief measure for screening complicated grief: reliability and discriminant validity. PLoS One. 2012; 7:e31209. [PubMed: 22348057]

43. Johnson JG, First MB, Block S, et al. Stigmatization and receptivity to mental health services among recently bereaved adults. Death Stud. 2009; 33:691-711. [PubMed: 19697482]

44. Gupta S, Bonanno GA. Complicated grief and deficits in emotional expressive flexibility. J Abnorm Psychol. 2011; 120:635-643. [PubMed: 21766973]

45. Burton CL, Yan OH, Pat-Horenczyk R, et al. Coping flexibility and complicated grief: a comparison of American and Chinese samples. Depress Anxiety. 2012; 29:16-22. [PubMed: 21898713]

46. Golden AM, Dalgleish T. Facets of pejorative self-processing in complicated grief. J Consult Clin Psychol. 2012; 80:512-524. [PubMed: 22329823]

47*. Boelen PA. Personal goals and prolonged grief disorder symptoms. Clin Psychol Psychother. 2011; 18:439-444. Provides new understanding of the ability to form goals among individuals with complicated grief. [PubMed: 21125691]

48. Prigerson HG, Bierhals AJ, Kasl SV, et al. Traumatic grief as a risk factor for mental and physical morbidity. Am J Psychiatry. 1997; 154:616-623. [PubMed: 9137115]

49. Prigerson HG, Frank E, Kasl SV, et al. Complicated grief and bereavement-related depression as distinct disorders: preliminary empirical validation in elderly bereaved spouses. Am J Psychiatry. 1995; 152:22-30. [PubMed: 7802116]

50. Szanto K, Prigerson H, Houck P, Ehrenpreis L, Reynolds CF 3rd. Suicidal ideation in elderly bereaved: the role of complicated grief. Suicide Life Threat Behav. 1997; 27:194-207. [PubMed: 9260302] 
51. Piper, WE.; Ogrodniczuk, JS.; Joyce, AS.; Weideman, R., editors. Risk factors for complicated grief. Washington, DC: American Psychological Association; 2011.

52. Lobb EA, Kristjanson L, Aoun SM, et al. Predictors of complicated grief: A systematic review of empirical studies. Death Stud. 2010; 34:673-698.

53. Hibberd R, Elwod LS, Galovski TE. Risk and protective factors for postraumatic stress disorder, prolonged grief, and depression in survivors of the violent death of a loved one. J Loss Trauma. 2010; 15:426-447.

54. Kramer BJ, Kavanaugh M, Trentham-Dietz A, Walsh M, Yonker JA. Complicated grief symptoms in caregivers of persons with lung cancer: the role of family conflict, intrapsychic strains, and hospice utilization. Omega (Westport). 2010; 62:201-220. [PubMed: 21495532]

55. Kristensen PL, Weisaeth L, Heir T. Predictors of Complicated Grief After a Natural Disaster: A Population Study Two Years After the 2004 South-East Asian Tsunami. Death Stud. 2010; 34:137-150.

56. Lombardo L, Morelli E, Luciani M, et al. Pre-loss demographic and psychological predictors of complicated grief among relatives of terminally ill cancer patients. Psychother Psychosom. 2012; 81:256-258. [PubMed: 22678231]

57. Tomarken A, Holland J, Schachter S, et al. Factors of complicated grief pre-death in caregivers of cancer patients. Psychooncology. 2008; 17:105-111. [PubMed: 17443644]

58. Schaal S, Jacob N, Dusingizemungu JP, Elbert T. Rates and risks for prolonged grief disorder in a sample of orphaned and widowed genocide survivors. BMC Psychiatry. 2010; 10:55. [PubMed: 20604936]

59. Seirmarco G, Neria Y, Insel B, et al. Religiosity and mental health: Changes in religious beliefs, complicated grief, posttraumatic stress disorder, and major depression following the September 11, 2001 attacks. Psycholog Relig Spiritual. 2012; 4:10-18.

60. Chiu YW, Huang CT, Yin SM, et al. Determinants of complicated grief in caregivers who cared for terminal cancer patients. Support Care Cancer. 2010; 18:1321-1327. [PubMed: 19816716]

61. Denckla CA, Mancini AD, Bornstein RF, Bonanno GA. Adaptive and Maladaptive Dependency in Bereavement: Distinguishing Prolonged and Resolved Grief Trajectories. Pers Individ Dif. 2011; 51:1012-1017. [PubMed: 21984858]

62. Fujisawa D, Miyashita M, Nakajima S, et al. Prevalence and determinants of complicated grief in general population. J Affect Disord. 2010; 127:352-358. [PubMed: 20580096]

63. Boelen PA, de Keijser J, van den Hout MA, van den Bout J. Treatment of complicated grief: a comparison between cognitive-behavioral therapy and supportive counseling. J Consult Clin Psychol. 2007; 75:277-284. [PubMed: 17469885]

64*. Acierno R, Rheingold A, Amstadter A, et al. Behavioral activation and therapeutic exposure for bereavement in older adults. Am J Hosp Palliat Care. 2012; 29:13-25. Describes a trial testing behavioral activation treatment for complicated grief. [PubMed: 21685428]

65. Asukai N, Tsuruta N, Saito A. Pilot study on traumatic grief treatment program for Japanese women bereaved by violent death. J Trauma Stress. 2011; 24:470-473. [PubMed: 21780192]

66. Rosner R, Pfoh G, Kotoucova M. Treatment of complicated grief. Eur J Psychotraumatol. 2011:2.

67. Papa A, Sewell MT, Garrison-Diehn C, Rummel C. A randomized open trial assessing the feasibility of behavioral activation for pathological grief responding. Behavior Therapy. 2013

68*. Supiano KP, Luptak M. Complicated Grief in Older Adults: A Randomized Controlled Trial of Complicated Grief Group Therapy. Gerontologist. 2013 Describes the adapatation of Shear et al.'s complicated grief treatment for group therapy.

69. Wagner B, Knaevelsrud C, Maercker A. Internet-based cognitive-behavioral therapy for complicated grief: a randomized controlled trial. Death Stud. 2006; 30:429-453. [PubMed: 16610157]

70. Zygmont M, Prigerson HG, Houck PR, et al. A post hoc comparison of paroxetine and nortriptyline for symptoms of traumatic grief. J Clin Psychiatry. 1998; 59:241-245. [PubMed: 9632035]

71. Pasternak RE, Reynolds CF 3rd, Schlernitzauer M, et al. Acute open-trial nortriptyline therapy of bereavement-related depression in late life. J Clin Psychiatry. 1991; 52:307-310. [PubMed: 2071562] 
72. Hensley PL, Slonimski CK, Uhlenhuth EH, Clayton PJ. Escitalopram: an open-label study of bereavement-related depression and grief. J Affect Disord. 2009; 113:142-149. [PubMed: 18597854] 


\section{TABLE 1}

\section{DSM-5 Criteria for Persistent Complex Bereavement Disorder}

A. The individual experienced the death of someone with whom he or she had a close relationship.

B. Since the death, at least one of the following symptoms is experienced on more days than not and to a clinically significant degree and has persisted for at least 12 months after the death in the case of bereaved adults and 6 months for bereaved children:
1. Persistent yearning/longing for the deceased.
2. Intense sorrow and emotional pain in response to the death.
3. Preoccupation with the deceased.
4. Preoccupation with the circumstances of the death.

C. Since the death at least six of the following symptoms are experienced on more days than not and to a clinically significant degree, and have persisted for at least 12 months after the death in the case of bereaved adults and 6 months for bereaved children:

Reactive distress to the death

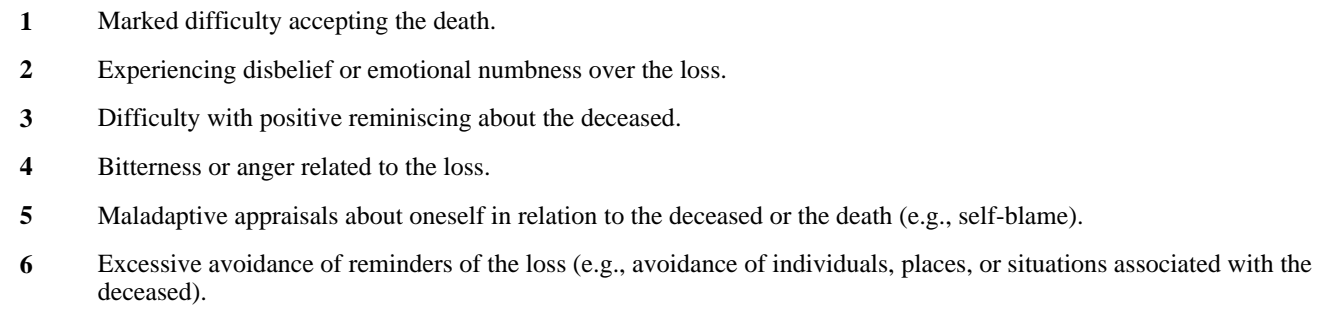

$7 \quad$ A desire to die in order to be with the deceased.

8 Difficulty trusting other individuals since the death.

9 Feeling alone or detached from other individuals since the death.

10 Feeling that life is meaningless or empty without the deceased, or the belief that one cannot function without the deceased.

11 Confusion about one's role in life or a diminished sense of one's identity (e.g., feeling that a part of oneself died with the deceased)

12 Difficulty or reluctance to pursue interests since the loss or to plan for the future (e.g., friendships, activities)

D. The disturbance causes clinically significant distress or impairment in social, occupational, or other important areas of functioning.

E. The bereavement reaction is out of proportion to or inconsistent with cultural or religious, or age-appropriate norms.

Specify if: With traumatic bereavement: Bereavement due to homicide or suicide with persistent distressing preoccupations regarding the traumatic nature of the death (often in response to loss reminders), including the deceased's last moments, degree of suffering and mutilating injury, or the malicious or intentional nature of the death.

Reproduced with permission from American Psychiatric Association [28]: Diagnostic and statistical manual of mental disorders, fifth edition. Arlington, VA: American Psychiatric Association, 2013. 
TABLE 2

Comparison of Major Depressive Disorder and Complicated Grief

\begin{tabular}{ll}
\hline MAJOR DEPRESSIVE DISORDER & COMPLICATED GRIEF \\
\hline Pervasive sad mood & Sadness related to missing the deceased \\
Loss of interest or pleasure in most activities & $\begin{array}{l}\text { Strong interest in the deceased maintained } \\
\text { Guilt related to the death or deceased }\end{array}$ \\
Pervasive sense of guilt & Self-criticism only related to the loss \\
Low self-esteem & $\begin{array}{l}\text { Suicidal thoughts focused on not wanting to live without the deceased or a } \\
\text { wish to rejoin the deceased }\end{array}$ \\
$\begin{array}{l}\text { Suicidal thoughts related to a range of negative emotions and } \\
\text { cognitions }\end{array}$ & $\begin{array}{l}\text { Avoidance of situations and people related to reminders of the loss } \\
\text { Not seen in depression }\end{array}$ \\
Not seen in depression & Intense yearning for the person who died \\
Adapted from Shear \& Mulhare [73]. &
\end{tabular}

